\section{Prepared for a Disaster?}

The Moorgate tube-train disaster was an incident which created difficulties from every conceivable angle and confirmed many of the problems to be experienced in disaster management generally. On page 727 the medical staff concerned with the handling of this most unfortunate incident describe some of the problems they encountered.

From the outset it was difficult to assess the magnitude of the accident, and particular problems were experienced in gaining access to the casualties. Lighting and ventilation were required in the confined area of the rescue, and the equipment providing these facilities, together with the cutting equipment, generated noise which in turn added to the difficulties of communication underground. In spite of these and many other problems 74 live patients were evacuated in 13 hours, including one who required an on-site amputation to effect her release. An emergency resuscitation area was established on the underground platform, and the efficiency of the sorting and resuscitation by the medical teams was reflected by the fact that only two casualties reaching hospital were dead on arrival and by the absence of airway problems among all those who were alive.

Every district general hospital in Britain has a disaster scheme, so that it could be assumed that they are adequately prepared for major accidents. However, the mere presence of a paper plan does nothing to guarantee that it is up to date, comprehensive, and understood by all levels of staff. Rutherford has shown ${ }^{1}$ that we in Britain can expect an incident of disaster proportions (with live casualties varying in number from 6 to 217) to occur on average at the rate of two per year, and herein lies one of the main problems: persuading everyone to accept that a disaster may happen in their area and to devote sufficient time, effort, and resources to the plan.

The next major problem to contend with was identified at a symposium on Disaster Planning held at Haslar in 1974. There is no nationally agreed uniform standard covering terminology, definition of priorities, identification of key staff, equipment, or interservice co-ordination. Standardization would, for instance, provide junior staff with the incentive to learn and the knowledge to act as they move from job to job and area to area. Co-ordination between services would ensure that the needs of one service were met by the actions of another. A report on the Moorgate crash in the Fire Service Journal Fire made the point ${ }^{3}$ that "a system of clearly marking dead victims inside the wreckage would have been appreciated by most personnel since time was wasted by different crews checking the same fatalities." A strong plea was rightly made at the end of the Haslar symposium for a national policy to be formed for the medical aspects of disaster management. Indeed, when the medical contribution to this field is compared with that of the emergency services the deficiencies are clear. The fire, police, and ambulance services spend time and money on planning and research in this aspect of their responsibilities and officers have certain functions delegated to them and exchange information with other authorities.

In the medical field the responsibilities are less clearly defined. Nationally there is no agreement on basic terms and definitions; regional authorities have the opportunity to coordinate area and district plans, resources, and facilities, but it is at local level that the next major deficiency occurs. Who teaches the new and changing staff their role, includes the general practitioners of the district, co-ordinates with the emergency services, updates the equipment, implements findings from reports of disasters in other areas, and ensures that the psychiatric registrar with no experience of trauma is not the mobile team leader? In short, who has the personal interest and responsibility for the practical detail of disaster management?

The often-held view that any doctor can organize accident and emergency work has not been borne out by practical experience in the past. With the appointment of 100 new consultants in accident and emergency in the last few years there is surely a case for attaching the clinical responsibility for such co-ordination to this hospital post. Given sessional time and responsibility, such a consultant would be able to work in close harmony with the community physician and be responsible to a committee. In the absence of the direct stimulus of experiencing a disaster the best alternative is responsibility. This coupled with postgraduate lecture time for talks by visiting speakers with direct experience, together with publication of papers by the services concerned-such as that in this issue-should focus further attention on the problems.

One further method of familiarization with the routines and techniques required in rescue work would be for hospitals to accept some small part in the provision of medical attendance at ordinary accidents where casualties are trapped. By a degree of participation in such small procedures on a more regular basis the equipment in the cupboard and its packaging, the clothing, the co-ordination with the other services, and the techniques of rescue would be tried, evolved, practised, learned, and respected. Come the disaster, the planned response should then be more efficient, and the lives of more patients may be saved. Such participation would cost little, as the equipment is already in existence in the disaster cupboard. Details of operational and managerial procedures have been described in several recent publications, ${ }^{3-8}$ so it is evident that the techniques for disaster management are already in existence-what is urgently required is the national definition of terms and standards together with the local delegation of responsibility for their implementation and supervision.

These changes are more than ever important in the absence of a civil defence organization, for only when such basic requirements have been met can it be assumed that all areas are adequately prepared for a disaster.

1 Rutherford, W. H., Injury, 1973, 4, 189

2 Ed. J. W. Richardson, Disaster Planning-A Symposium Report. Bristol, Wright, 1975.

${ }^{3}$ Moorgate Special Report, Fire-Fournal of the Fire Protection Profession, $1975,68,1$.

4 Ed. W. Sillar, A Guide to Disaster Management. Glasgow, Action for Disaster, 1974.

${ }^{5}$ Disaster Management (tape/slide), Medical Recording Service Foundation. London, Royal College of General Practitioners, 1975.

6 Surgery of Violence. London, British Medical Association, 1975.

7 Snook, R., Medical Aid at Accidents. London, Update Publications, 1974.

${ }^{8}$ Savage, P E. A., British Medical fournal, 1972, 3, 42.

\section{Toxic Megacolon may Complicate Crohn's Disease}

Acute toxic dilatation of the colon is one of the major threats to life in ulcerative colitis, with an estimated incidence of $2-13 \%$ in patients with the condition in the United Kingdom. ${ }^{12}$ However, it is now known that it may develop in other diseases such as amoebic colitis, ischaemic colitis, pseudomembranous enterocolitis, typhoid fever, bacillary 
dysentery, and cholera. ${ }^{3-5}$ At one time toxic megacolon was thought to spare patients with Crohn's disease of the colon, and all those patients who developed it were assumed to have ulcerative colitis; but in 1967 the first detailed case report was published from $\mathrm{Chicago}^{6}$ and further histories have since confirmed the association.

Any patient with severe colitis may develop toxic dilatation, which is characterized by abdominal distension, tenderness, signs of peritonism, and sometimes a paradoxical fall in stool frequency. Unfortunately, abdominal distension may not be prominent, so that diagnosis must be confirmed by a plain abdominal radiograph; the film frequently discloses an unexpectedly large degree of dilatation. The transverse colon is often but not invariably the site of distension; a diameter of more than $5.5 \mathrm{~cm}$ is considered abnormal. ${ }^{7}$ The presence of toxaemia can be assessed by fever (greater than $38.6^{\circ} \mathrm{C}$ ), tachycardia (more than $120 / \mathrm{min}$ ), leucocytosis (at least $10.5 \times 10^{9} / 1$ ), anaemia (haemoglobin less than $9.0 \mathrm{~g} / \mathrm{dl}$ ), dehydration, mental changes, hypotension, and electrolyte disturbances. ${ }^{2}$ This serious condition may be worsened by perforation of the colon, bacteraemia, and intracolonic haemorrhage. The overall mortality is therefore about $30 \%$ even with intensive medical therapy and rises to $82 \%$ once perforation has occurred. ${ }^{8}$

This frightening mortality rate may be reduced by avoidance of precipitating factors, earlier diagnosis, and prompt operation. The cause of toxic megacolon is not known but it can follow the administration of a barium enema, or treatment with anticholinergic drugs and opiates such as tinct. opii, kaolin et morph., and codeine phosphate. These should all be avoided in active colitis. Hypokalaemia is now thought to follow and not cause the dilatation. Delay in diagnosis is still common ${ }^{3}$; the complication is particularly treacherous when it sneaks up on patients already undergoing treatment in hospital. Plain abdominal radiographs should therefore be performed daily on any patient severely ill with colitis; measurements to detect increasing abdominal girth are just not sufficient. Before dilatation occurs it should be possible to detect mucosal islands outlined against the gas in the lumen ${ }^{9}$-at this stage there is patchy loss of mucosa but the underlying muscle is not affected.

Recent reviews ${ }^{2} 81011$ have continued to stress the importance of early surgery in ulcerative colitis, and at present there is no reason for toxic megacolon of Crohn's disease to be treated differently. The patient should be given infusions of fluid-electrolytes, blood, and albumin-together with parenteral corticosteroids or corticotrophin and broad-spectrum antibiotics. Peroral intubation and decompression of the intestine are also essential; the tip of the tube should be placed beyond the stomach and preferably in the ileum. ${ }^{12}$ Medical treatment is the prelude to operation, and a surgeon should be consulted from the outset. Patients who fail to show clinical improvement within 4-6 hours must be operated on as an emergency; an elective operation may be performed on the others as soon as convenient. When perforation has occurred there should be no delay. Proctocolectomy remains the treatment of choice. It may prove possible to abort the attack in a number of patients without operation, but the colon remains severely damaged and will often require surgery for continuing chronic symptoms or further acute relapses, which may even be fatal. ${ }^{11}$

A recent study of 615 cases of Crohn's disease from the Cleveland Clinic ${ }^{13}$ showed that toxic megacolon developed in $4 \%$. No cases were found when the Crohn's disease was confined to the small intestine, but megacolon developed in $2 \%$ of those with ileocolic disease and its incidence rose to $11 \%$ when the disease was limited to the colon. Further analysis of these colonic cases showed that segmental colitis carried an incidence of $6 \%$ compared with $13 \%$ when the entire colon was affected. Toxic megacolon was one of the major indications for surgery, but the results were not reported. A smaller series of 160 patients from the Mount Sinai Hospital, New York, ${ }^{14}$ produced seven patients with toxic megacolon; the incidence was $2 \%$ in ileocolitis but $13 \%$ in colitis. The authors suggest that the mortality may be less than in ulcerative colitis. Two patients recovered with medical therapy, which included intubation with decompression, hydrocortisone, and ampicillin or kanamycin. However, most patients required surgery, though a diversion operation was thought to be sufficient.

Crohn's disease remains full of surprises, and the clinical appearance of toxic megacolon may not always be what it seems. In 1972 Greene and his colleagues ${ }^{15}$ described two patients with rapid onset of abdominal distension, pain, tenderness, diarrhoea, and toxaemia during the course of Crohn's disease. Radiographs showed ulceration, oedema, and acute dilatation limited to the ileum without evidence of intestinal obstruction. Intensive medical therapy produced dramatic clinical and radiological improvement. Time will show whether toxic mega-ileum is a distinct entity in inflammatory bowel disease, but it does appear that toxic megacolon is an established feature of Crohn's disease.

${ }^{1}$ Edwards, F. C., and Truelove, S. C., Gut, 1964, 5, 1.

2 Jalan, K. N., et al., Gastroenterology, 1969, 56, 583.

3 Kirsner, J. B., Gastroenterology, 1974, 66, 1088.

4 Wruble, L. D., et al., New England fournal of Medicine, 1966, 275, 926.

Brown, C. H., Ferrante, W. A., and Davis, W. D., American fournal of Digestive Diseases, 1968, 13, 813.

${ }^{6}$ Schacter, H., Goldstein, M. J., and Kirsner, J. B., Gastroenterology, 1967, $53,136$.

7 Jones, J. H., and Chapman, M., Gut, 1969, 10, 562.

${ }^{8}$ Binder, S. C., Patterson, J. F., and Glotzer, D. J., Gastroenterology, 1974, 66, 909.

9 Brooke, B. N., and Sampson, P. A., Lancet, 1964, 2, 1272.

10 Norland, C. C., and Kirsner, J. B., Medicine, 1969, 48, 229.

11 Adams, J. T., Archives of Surgery, 1973, 106, 678.

12 Neschis, M., Siegelman, S. S., and Parker, J., Gastroenterology, 1968 , $55,251$.

${ }^{13}$ Farmer, R. G., Hawk, W. A., and Turnbull, R. B., Gastroenterology, $1975,68,627$.

14 Greenstein, A. J., Kark, A. E., and Dreiling, D. A., American fournal of Gastroenterology, 1974, 62, 419.

15 Greene, L., Kresch, L., and Held, B., American fournal of Digestive Diseases, 1972, 17, 439.

\section{Phenformin and Hypertension}

Phenformin, a drug with many actions, is used widely in the management of maturity-onset diabetics, many of whom are elderly and obese. The University Group Diabetes Program (U.G.D.P.) has claimed recently to have shown that this drug raises blood pressure. ${ }^{1}$ Glucose intolerance is a risk factor for cardiovascular disease which, though independent of associated atherogenic traits, is of more significance when such traits are present, ${ }^{2}$ so the claim is a serious one. It is, moreover, supported by the observation that there were over twice as many cardiovascular deaths in the group of 204 patients treated with phenformin followed up by the group as in 197 control adult-onset diabetics given placebo or insulin. Increases in cardiovascular mortality, blood pressure, and also the use of digitalis were first reported ${ }^{3}$ by the U.G.D.P. in 1971, and prompted the withdrawal of phenformin from the trial. 